\title{
Misdiagnosis, Mistreatment, and Harm — When Medical Care Ignores Social Forces
}

Seth M. Holmes, Ph.D., M.D., Helena Hansen, M.D., Ph.D., Angela Jenks, Ph.D., Scott D. Stonington, M.D., Ph.D., Michelle Morse, M.D., M.P.H., Jeremy A. Greene, M.D., Ph.D., Keith A. Wailoo, Ph.D., Michael G. Marmot, M.B., B.S., Ph.D., and Paul E. Farmer, M.D., Ph.D.

Tn a 2019 op-ed in the Wall Street Journal entitled "Take Two Aspirin and Call Me by My Pronouns," former University of Pennsylvania Dean of Medical Education Stanley Goldfarb echoed a dismissal that some physicians have been voicing for decades. Why should medical training focus on social factors, Goldfarb asked, when medicine's purpose is to cure individual patients? His essay assumed that one can effectively cure patients while ignoring the world in which they live. Unfortunately, that is an empirically untenable position.

Between November 2018 and January 2020, the New England Journal of Medicine published monthly Case Studies in Social Medicine, exploring concepts from the social sciences that can help us respond to the influence of social factors in the practice of medicine (see table). These cases were developed to demonstrate how clinicians can help manage social forces and their health effects. In addition, we found that the articles help demonstrate that without the skills to identify and respond to those forces, physicians are at risk of misdiagnosing, mistreating, and ultimately causing harm. When physicians use only biologic or individual behavioral interventions to treat diseases that stem from or are exacerbated by social factors, we risk harming the patients we seek to serve.

Social, political, and economic structures - those highlighted by Goldfarb as well as structural racism, settler colonialism, other structures of marginalization, and the inequalities each of these produces - are injuring and killing people. To stop these pro- cesses, we need a range of community- and team-based interventions, many of which occur beyond clinical practice - such as urban and regional planning to ensure the availability of safe housing and healthy food, and policy and systems changes to guarantee fair access to gainful employment and protection from environmental degradation. As clinicians, we endeavor to treat our patients' diseases and injuries. But when we dismiss social factors as peripheral, we not only miss opportunities to improve outcomes, we may in fact fail at medicine's core responsibilities to diagnose and treat illness and to do no harm.

Physicians risk misdiagnosis when we fail to take social structures into account or misattribute their effects to biologic mechanisms or individual behaviors. A 


\begin{tabular}{|c|c|}
\hline \multicolumn{2}{|c|}{ Case Studies in Social Medicine Series.* } \\
\hline Case & Social Concept \\
\hline \multicolumn{2}{|c|}{$\begin{array}{l}\text { Treating the fundamental drivers of } \\
\text { patient health }\end{array}$} \\
\hline Carrasco et al. & Misrecognition and critical consciousness \\
\hline Seymour et al. & Structural differential \\
\hline Knight et al. & Reproductive (in) justice \\
\hline Karandinos et al. & Structural violence of hyperincarceration \\
\hline Pallok et al. & Structural racism \\
\hline \multicolumn{2}{|c|}{$\begin{array}{l}\text { Navigating structural and bureaucratic } \\
\text { barriers to care }\end{array}$} \\
\hline Stonington et al. & Structural iatrogenesis \\
\hline Berlin et al. & The right and left hands of the state \\
\hline Braslow et al. & Medicalization and demedicalization \\
\hline Madaras et al. & Social distance and mobility \\
\hline Kalofonos & Biological citizenship \\
\hline \multicolumn{2}{|c|}{$\begin{array}{l}\text { Critically applying medical knowledge } \\
\text { and categories }\end{array}$} \\
\hline Friedner et al. & Disability justice and multiple normals \\
\hline Stroumsa et al. & The power and limits of classification \\
\hline Aronowitz et al. & Contingent knowledge and looping effects \\
\hline Béhague et al. & Dialogic praxis \\
\hline Chowdhury et al. & Democratizing evidence production \\
\hline
\end{tabular}

* The series was introduced in a Medicine and Society article by Stonington et al. (Case Studies in Social Medicine - Attending to Structural Forces in Clinical Practice. N Engl J Med 2018;379:1958-61).

well-recognized example of largescale misdiagnosis involves the multiple, intertwined epidemics of chronic disease that are related to housing and food insecurity in low-income neighborhoods. These diseases - including diabetes, heart disease, obesity, asthma, mood and anxiety disorders, and substance use disorder - cluster together sociogeographically into what have been termed "syndemics." "Dietary counseling" may be farcical when patients with diabetes cannot acquire lean proteins and vegetables. And escalating doses of inhaled asthma medication may be futile for children living in high-allergen or environmentally contaminated have persuaded the states of Oregon, New York, and Massachusetts to devote Medicaid spending to affordable, safe housing and have reduced food insecurity in U.S. cities through clinic- and community-based food-access programs.

Without acknowledging or responding to social structures, clinicians may perpetuate mistreatment, providing ineffective responses to our patients' medical problems. There are aspects of peoples' lives outside medical care that determine whether they get sick and how well or poorly our treatments "fit" them. These social forces are also active within medicine, determining whom we treat, how we treat them, where we put hospitals and clinics, which specialties and caregivers we prioritize and fund, and what goals we set for treatment.

One example involves clinicians' necessary interactions with financial institutions such as insurance companies, which affect some patients more negatively than others, depending on their socioeconomic, immigration, racial, colonized, or other marginalized status. In one documented case, a patient with gastric cancer underwent biopsy and imaging for staging and chemotherapy planning and then had to wait 3 months for insurance approval. By that time, lab tests revealed worsened liver function and increased levels of tumor markers and repeat imaging showed new metastases necessitating altered chemotherapy and radiation regimens. This change in prescription required another 3-month wait for approval, and the patient died without receiving a single medication. ${ }^{2}$

Such financially motivated restrictions are just one instance of 
social, political, and economic structures leading to inappropriate treatments and poor outcomes. Training in social medicine and structural competency can prepare clinicians to identify such constraints and work toward solutions for their patients and practices. Many clinicians, for example, play important roles in growing social movements for health care access for all.

Beyond misdiagnosis and mistreatment, medical care that ignores social structures may cause patients real and measurable

prescribe opioids in response, rather than to investigate and collaboratively address the social problems leading our patients to seek these prescriptions. A clinical workforce educated in social medicine principles would be more skilled in questioning the corporate influences that propagated inappropriate opioid prescribing, while identifying and intervening in the social drivers of demand for opioids.

The centrality of social factors in clinical care has long been recognized by physicians - from

\section{When chronic conditions are viewed as solely biologic or behavioral malfunction, the diagnosis misses the true causes, and often, misdiagnosis leads to ineffective treatments.}

harm, in a manner similar to the iatrogenic harms of medical mistakes. One example is the role of physicians in the ongoing opioid epidemic. The aggressive marketing of opioids by the pharmaceutical industry and false claims used to gain Food and Drug Administration approval have been widely publicized. And physicians who have failed to change patterns of inappropriate pain management are increasingly the targets of lawsuits and public anger. More broadly, population health researchers point to social conditions such as postindustrial unemployment and disintegration of social networks and community institutions as the root causes of epidemic pain and reliance on narcotics, recognizing opioid overdoses as "deaths of despair." sicians are front-line witnesses to community-level despair, but we are generally equipped only to
Rudolf Virchow, the 19th-century "founder of modern pathology," who traced typhoid epidemics to living conditions in central Europe, to leaders of the Association of American Medical Colleges and the Institute of Medicine (now the National Academy of Medicine), who have issued position statements on this topic. The National Research Council recently reported that the United States spends more money on health care than any other country yet has the poorest health outcomes among peer nations, largely owing to social structural factors.

Inequitable social structures not only harm patients; they also subvert our attempts to provide effective care. In fact, among the growing number of physicians who report experiencing burnout or even leaving clinical practice, many cite systemic barriers to ef- fective care as an important factor. The Robert Wood Johnson Foundation has reported that the vast majority of physicians nationwide identify social factors as critical to clinical outcomes but indicate a need for tools for addressing the social drivers of health and illness. There is enormous progress to be made, given that the majority of U.S. medical schools and residency programs lack faculty with expertise in social medicine, curricula for teaching it, and training sites where it is practiced.

Clinicians are uniquely positioned to respond to the social, political, and economic structures affecting our patients' health. If we fail to do so, we risk misdiagnosis, mistreatment, and iatrogenic harm. We are convinced that undergraduate, graduate, and continuing medical education in structural competency and other social medicine frameworks ${ }^{4}$ can be used to train clinicians who will thrive while effectively confronting the health problems caused by inequitable social structures. ${ }^{5}$ A grasp of such frameworks would lead physicians to interact differently with patients, communities, interprofessional teams, health care systems, and the societies and world in which we live. Then millions of patients could receive medical care that is effective and does no harm.

Disclosure forms provided by the authors are available at NEJM.org.

From the University of California Berkeley, Berkeley, and the University of California San Francisco, San Francisco (S.M.H.); New York University, New York (H.H.); the University of California Irvine, Irvine (A.J.); the University of Michigan, Ann Arbor (S.D.S.); Brigham and Women's Hospital and Harvard Medical School - both in Boston (M.M., P.E.F.); Johns Hopkins University, Baltimore (J.A.G.); Princeton University, Princeton, NJ (K.A.W.); and University College London, London (M.G.M.). 
1. Singer M, Bulled N, Ostrach B, Mendenhall E. Syndemics and the biosocial conception of health. Lancet 2017;389:941-50.

2. Sanz C. Out-of-sync cancer care: health insurance companies, biomedical practices, and clinical time in Colombia. Med Anthropol 2017;36:187-201.
3. Dasgupta N, Beletsky L, Ciccarone D. Opioid crisis: no easy fix to its social and economic determinants. Am J Public Health 2018;108:182-6.

4. Kleinman A. Four social theories for global health. Lancet 2010;375:1518-9.

5. Hansen H, Metzl M, eds. Structural competency in mental health and medicine: a case-based approach to treating the social determinants of health. Cham, Switzerland: Springer, 2109.

DOI: 10.1056/NEJMp1916269

Copyright (c) 2020 Massachusetts Medical Society. 